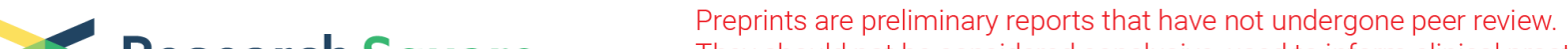 Research Square They should not be considered conclusive, used to inform clinical practice, or referenced by the media as validated information.
}

\section{Optimization of the Flow Conditions in the Spawning Grounds of the Chinese Sturgeon (Acipenser Sinensis) Through Gezhouba Dam Generating Units}

\author{
Anyang Huang \\ China Three Gorges Corporation (China) \\ Jinzhong Yao \\ China Three Gorges Corporation (China) \\ Jiazhi Zhu \\ China Three Gorges Corporation (China)

\section{Xingchen Gao} \\ China Three Gorges Corporation (China) \\ Wei Jiang ( $\sim$ jiangwei0309@qq.com ) \\ China Three Gorges Corporation (China)
}

\section{Research Article}

Keywords: Chinese sturgeon, spawning ground, field monitoring, numerical simulation, Gezhouba Dam generator units, suitable velocity

Posted Date: January 19th, 2021

DOl: https://doi.org/10.21203/rs.3.rs-145619/v1

License: (c) (1) This work is licensed under a Creative Commons Attribution 4.0 International License.

Read Full License

Version of Record: A version of this preprint was published at Scientific Reports on July 13th, 2021. See the published version at https://doi.org/10.1038/s41598-021-93903-4. 


\section{Abstract}

Chinese sturgeon (Acipenser sinensis) is a critically endangered species, and waters downstream from Gezhouba Dam are the only known spawning grounds. To optimize the velocity conditions in the spawning grounds by controlling the opening mode of Gezhouba Dam generator units, a mathematical model of Chinese sturgeon spawning grounds was established in FLOW-3D. The model was evaluated with velocity measurements, and the results was determined to be in good agreement. By inverting the 2016-2019 field monitoring results, the model shows that the preferred velocity range for Chinese sturgeon spawning is $0.6-1.5 \mathrm{~m} / \mathrm{s}$. Velocity fields of different opening modes of the generator units were simulated with identical discharge. The suitable-velocity area was maximal when all units of Dajiang Plant of Gezhouba Dam were open. For discharges below $12000 \mathrm{~m}^{3} / \mathrm{s}$, most of the area was suitable; for discharges above $12000 \mathrm{~m}^{3} / \mathrm{s}$, the suitable area rapidly decreased with increasing discharge. A comparison of suitable areas under high-flow showed that at discharges of $12000 \sim 15000 \mathrm{~m}^{3} / \mathrm{s}$, opening $11 \sim 13$ units on the left side was optimal. For discharges above $15000 \mathrm{~m}^{3} / \mathrm{s}$, all units should be open. We used these results to recommend a new operation scheme to support the conservation of Chinese sturgeon.

\section{Introduction}

The Gezhouba Dam Project is the first hydropower station on the Yangtze River. The dam is intended to provide multiple benefits to society, including power generation and preventing flooding or drought. However, dams may also change the transport of water and sediment ${ }^{1}$, which affects the fish habitats as in the case of the required habitats of Chinese sturgeon (Acipenser sinensis) ${ }^{2,3}$. The Chinese sturgeon is a large anadromous fish, a national first-class protection animal and a critically endangered species ${ }^{4}$. Before the construction of Gezhouba Dam, the spawning grounds of the Chinese sturgeon were mainly in the lower reaches of the Jinsha River and upper reaches of the Yangtze River ${ }^{5}$. After the closure of Gezhouba Dam, the sturgeon selected a new spawning ground in the waters downstream of Gezhouba Dam, which now represents the only known Chinese sturgeon spawning ground ${ }^{6}$. According to the results of continuous monitoring in recent years, the reproductive geographic range and amounts of Chinese sturgeon has substantially decreased ${ }^{4,7}$.

Efforts to conserve the Chinese sturgeon have focused on determining suitable hydrologic or hydraulic conditions of the spawning ground. One of the hydraulic environmental variables thought to be important for reproduction is the flow velocity in the spawning habitat. A previous study has shown that the Chinese sturgeon will actively select flow velocity conditions that are beneficial to its habitat and reproduction, and flow velocities exceeding the maximum tolerable velocity of the fish will affect the normal habitat ${ }^{9}$. Research on the flow velocity of the spawning ground of Chinese sturgeon has mainly focused on two aspects: historical data of field measurements ${ }^{10-13}$ and numerical simulation ${ }^{14-17}$. In addition, the effect of the dam operation on the characteristics of water flow in the spawning grounds has been studied ${ }^{18-20}$, but few improvement measures and methods have been proposed. The waters downstream from 
Gezhouba Dam are the only known spawning grounds of Chinese sturgeon, but the sensitivity of the velocity fields to the operating modes of Gezhouba Dam is unclear. The purpose of this study is to determine how to optimize releases from the dam to improve the spawning habitat.

We continuously monitored the spawning ground of Chinese sturgeon every year from 1982 during the prospective spawning period. To effectively model links from dam operations to the spawning habitat, we used a combination of numerical simulation and field monitoring. Chinese sturgeon is a type of benthic fish. After its eggs are washed away by water, they adhere to the cracks in the bottom and hatch. Therefore, the bottom hydraulic parameters are more significant than the two-dimensional vertical average hydraulic parameters ${ }^{8}$. A mathematical model of the three-dimensional (3D) hydrodynamics of the spawning ground of Chinese sturgeon was established. The velocity field experienced by Chinese sturgeon 2016-2019 was determined by comparing the hydroacoustic locations of fish with the model results. From this comparison, we estimated the preferred velocity range for spawning of the Chinese sturgeon. Furthermore, the optimal scheme of different generating units of Gezhouba Dam was simulated and analysed to form recommendations for alternative release procedures to support the reproduction of the sturgeon.

\section{Results}

Flow velocity threshold. There were 92 Chinese sturgeon signals in 2016-2019, which were identified with the DIDSON dual-frequency video sonar system. The flow field of each sturgeon signal was simulated by the model, and the velocity of each signal location was obtained. According to the statistical analysis of the flow velocity values, the frequency of the sturgeon signal at different flow velocity values is shown in Fig. 1 . The results show that most signals were concentrated in areas with flow velocities of $0.6 \sim 1.5 \mathrm{~m} / \mathrm{s}$, which accounted for $88.1 \%$ of the signals; areas with flow velocities below $0.6 \mathrm{~m} / \mathrm{s}$ accounted for $4.3 \%$ of the signals, and areas with flow velocities above $1.5 \mathrm{~m} / \mathrm{s}$ accounted for $7.6 \%$. Therefore, $0.6 \sim 1.5 \mathrm{~m} / \mathrm{s}$ was selected as the preferred flow velocity range of the Chinese sturgeon for spawning activity.

Different opening modes with identical discharge. The discharge of $6150 \mathrm{~m}^{3} / \mathrm{s}$ on November 24,2016 , when the latest wild reproduction of Chinese sturgeon occurred, was used to study the flow velocity distribution with different opening modes. The specific opening mode cases are shown in Table 1. Case 1 was the actual situation, and the Dajiang Plant featured 7 open units: $\# 8, \# 11, \# 13, \# 14, \# 16, \# 19$, and \#21. According to the amounts of electricity generated by Dajiang Plant and Erjiang Plant on that day, the proportion of the Dajiang River flow was $58.8 \%$, and the average discharge of each unit was $516.6 \mathrm{~m}^{3} / \mathrm{s}$. Case 2 and case 3 featured 7 open units with the same discharge, but in case 2, units \#15 \#21 were continuously open on the right-side(facing downstream), and in case 3, units \#8 \#14 were continuously open near the left side. Case 4 and case 5 were the most concentrated conditions with the discharge of $6150 \mathrm{~m}^{3} / \mathrm{s}$ because the maximum through-discharge for each unit in the Dajiang Plant is $825 \mathrm{~m}^{3} / \mathrm{s}^{21}$. In these cases, at least 5 units were open with an average discharge of $723 \mathrm{~m}^{3} / \mathrm{s}$ per unit. Case 4 involved 
continuously opening units \#8 \#12 on the left side, and case 5 involved continuously opening units \#17 \#21 on the right side. Case 6 involved simultaneously opening 14 units on Dajiang River, and the average discharge of each unit was $258.3 \mathrm{~m}^{3} / \mathrm{s}$.

Table 1

Calculation cases with different opening modes of units under the identical discharge

\begin{tabular}{|lll|}
\hline $\begin{array}{l}\text { Case } \\
\text { No. }\end{array}$ & Opening mode of units & $\begin{array}{l}\text { discharge of each unit } \\
\left(\mathrm{m}^{3} / \mathrm{s}\right)\end{array}$ \\
\hline 1 & $\begin{array}{l}\text { Open } 7 \text { units according to the actual situation, } \# 8, \# 11, \# 13, \\
\# 14, \# 16, \# 19, \# 21\end{array}$ & 516.6 \\
\hline 2 & Open 7 units on the left, $\# 15 \sim 21$ & 516.6 \\
\hline 3 & Open 7 units on the right, $\# 8 \sim 14$ & 516.6 \\
\hline 4 & Open 5 units on the right, $\# 8 \sim 12$ & 723 \\
\hline 5 & Open 5 units on the left, $\# 17 \sim 21$ & 723 \\
\hline 6 & Open 14 units, $\# 8 \sim 21$ & 258.3 \\
\hline
\end{tabular}

Figure 2 shows the flow fields of the spawning ground under different opening modes with identical discharge, and the studied area is shown in Fig. 7d. By comparing the areas with a velocity threshold range of $0.6-1.5 \mathrm{~m} / \mathrm{s}$ in different cases, the most favourable opening mode was determined. In case 1 , the proportion of suitable area was $86.2 \%$. The velocity at the outlet of the units was higher than the $1.5 \mathrm{~m} / \mathrm{s}$ velocity threshold, but the discharge of each unit was only $516.6 \mathrm{~m}^{3} / \mathrm{s}$, so the high-velocity range was limited, and most areas were suitable. In case 2 and case 3 , there was a large difference in proportions of suitable area: $90.6 \%$ and $63 \%$, respectively. Because the left side was deeper than the right side, the flow velocity on the right side was higher under the same discharge, and case 3 more easily exceeded the flow threshold, which results in a larger unsuitable area. Case 2 was more suitable than case 1 , which also demonstrated that opening the left-side units was more favourable. In case 4 and case 5 , the proportions of suitable area were small: $61 \%$ and $72.5 \%$, respectively. Because the units were concentrated, the discharge of each unit was too high, and the outlet velocity was more than $2 \mathrm{~m} / \mathrm{s}$, so a large area of high velocity appears downstream of the units with backflow under the shut-down units. The proportion of suitable area in case 5 was larger than those in case 4 and case 3 , which further indicates that opening the left-side units was more favourable than opening the right-side units. Case 6, where all units were open, has a suitable-velocity area proportion of $95.9 \%$, which is greater than that of any other case. Because the discharge of each unit was only $258.3 \mathrm{~m}^{3} / \mathrm{s}$, the velocity of the unit outlet was less than $1.5 \mathrm{~m} / \mathrm{s}$, and almost all areas were suitable except for the small areas on both sides. The suitable-velocity area was the largest when all units of the Dajiang Plant of Gezhouba Dam were open; therefore, for a given discharge, it is best to open all units.

Different discharges under identical opening mode. The velocity distribution of the spawning field is affected by the opening mode of the units and discharge of Gezhouba Dam. To study the effect of 
different discharges, 14 cases were simulated, as shown in Table 2. All units of the Dajiang Plant were considered open because the proportion of suitable area was expected to be maximal under such circumstances. From 1982 to the present, the discharge during the spawning day of Chinese sturgeon under Gezhouba Dam has a wide range: the highest discharge was $27290 \mathrm{~m}^{3} / \mathrm{s}$ in 1990, and the lowest discharge was $5590 \mathrm{~m}^{3} / \mathrm{s}$ in 2012. However, the highest design discharge of the Gezhouba Dam units is $17930 \mathrm{~m}^{3} / \mathrm{s}^{22}$. Once the design discharge is exceeded, the spillway on Erjiang River discharges water, and the velocity distribution of the study area is not affected. Therefore, case 1 represents the lowest discharge of $5590 \mathrm{~m}^{3} / \mathrm{s}$, and case 2 represents a discharge of $6000 \mathrm{~m}^{3} / \mathrm{s}$. For each subsequent case, the discharge was increased by $1000 \mathrm{~m}^{3} / \mathrm{s}$ to case 13 with the highest flow of $17930 \mathrm{~m}^{3} / \mathrm{s}$. In case 14 , all units reached the design discharge, and the discharge of each unit was $825 \mathrm{~m}^{3} / \mathrm{s}^{21}$.

Table 2

Calculation cases with the same opening mode under different discharges

\begin{tabular}{|c|c|c|c|}
\hline Case No. & discharge $\left(\mathrm{m}^{3} / \mathrm{s}\right)$ & Opening mode of units & discharge of each unit $\left(\mathrm{m}^{3} / \mathrm{s}\right)$ \\
\hline 1 & 5590 & Open 14 units, \#8 21 & 243.2 \\
\hline 2 & 6000 & Open 14 units, \#8 21 & 252 \\
\hline 3 & 7000 & Open 14 units, \#8 21 & 294 \\
\hline 4 & 8000 & Open 14 units, \#8 21 & 336 \\
\hline 5 & 9000 & Open 14 units, \#8 21 & 378 \\
\hline 6 & 10000 & Open 14 units, \#8 21 & 420 \\
\hline 7 & 11000 & Open 14 units, \#8 21 & 462 \\
\hline 8 & 12000 & Open 14 units, \#8 21 & 504 \\
\hline 9 & 13000 & Open 14 units, \#8 21 & 546 \\
\hline 10 & 14000 & Open 14 units, \#8 21 & 588 \\
\hline 11 & 15000 & Open 14 units, \#8 21 & 630 \\
\hline 11 & 16000 & Open 14 units, \#8 21 & 672 \\
\hline 12 & 17000 & Open 14 units, \#8 21 & 714 \\
\hline 13 & 17930 & Open 14 units, \#8 21 & 753 \\
\hline 14 & $>17930$ & Open 14 units, \#8 21 & 825 \\
\hline
\end{tabular}

Figure 3 shows the proportion of suitable-velocity area with all units open under different discharges. According to the calculation results, the proportion of suitable area slightly fluctuated at approximately $96.2 \%$ for discharges of $5590-11000 \mathrm{~m}^{3} / \mathrm{s}$; the lowest value was $94.6 \%$ for a discharge of $10000 \mathrm{~m}^{3} / \mathrm{s}$, and the highest value was $98 \%$ for a discharge of $8000 \mathrm{~m}^{3} / \mathrm{s}$. Because the discharge of each unit was 
lower than $504 \mathrm{~m}^{3} / \mathrm{s}$, the velocity of the unit outlet was low, and most areas were within the velocity threshold. Therefore, it is advantageous to open all units when the discharge is low. After the discharge reached $12000 \mathrm{~m}^{3} / \mathrm{s}$, the proportion of suitable area rapidly decreased to $70.7 \%$ and gradually decreased with increases in discharge to $20.2 \%$ at a discharge of $17930 \mathrm{~m}^{3} / \mathrm{s}$. Because the discharge of each unit was higher than $504 \mathrm{~m}^{3} / \mathrm{s}$, on the right side of Dajiang River, the velocity of the unit outlet exceeded the velocity threshold and increased with increases in discharge, and the range of effect gradually increased. In the last case, the proportion of suitable area was only $6 \%$ when the units reached the designed discharge of $825 \mathrm{~m}^{3} / \mathrm{s}$. Because the discharge of each unit was too high, almost all areas exceeded the velocity threshold except for small areas on both sides. Therefore, at discharges below $12000 \mathrm{~m}^{3} / \mathrm{s}$, opening all units is favourable, and at discharge above $12000 \mathrm{~m}^{3} / \mathrm{s}$, a higher discharge corresponds to more unfavourable conditions.

Optimal scheme under high-flow conditions. High-flow conditions at Gezhouba Dam are considered those that exceed $12000 \mathrm{~m}^{3} / \mathrm{s}$ because of the substantive decline in suitable habitat area at higher discharges. Because opening the units on the left side of the Dajiang Plant provides a more uniform, suitable habitat, we evaluated 20 cases with a left-side opening mode under different discharge, as shown in Table 3 . Because the highest discharge of each unit in the Dajiang Plant is $825 \mathrm{~m}^{3} / \mathrm{s}$, at least 9 units must be open when the discharge is $12000 \mathrm{~m}^{3} / \mathrm{s}$. Case 1 was designed to open 9 units on the left, i.e., units $\# 13 \sim \# 21$, and the discharge of each unit was $784 \mathrm{~m}^{3} / \mathrm{s}$. Cases $2-5$ increased by 1 unit from left to right until 13 units were opened. For discharges of $13000 \mathrm{~m}^{3} / \mathrm{s}, 14000 \mathrm{~m}^{3} / \mathrm{s}, 15000 \mathrm{~m}^{3} / \mathrm{s}$, and $16000 \mathrm{~m}^{3} / \mathrm{s}$, at least $10,10,11$, and 12 units were opened. When the discharge was $17000 \mathrm{~m}^{3} / \mathrm{s}$ and $17930 \mathrm{~m}^{3} / \mathrm{s}$, at least 13 units were open. 
Table 3

Calculation cases with different opening modes under high-flow conditions

\begin{tabular}{|c|c|c|c|}
\hline Case No. & discharge $\left(\mathrm{m}^{3} / \mathrm{s}\right)$ & Opening mode of units & discharge of each unit $\left(\mathrm{m}^{3} / \mathrm{s}\right)$ \\
\hline 1 & 12000 & Open 9 units on the left, $\# 13 \sim 21$ & 784.0 \\
\hline 2 & 12000 & Open 10 units on the left, $\# 12 \sim 21$ & 705.6 \\
\hline 3 & 12000 & Open 11 units on the left, $\# 11 \sim 21$ & 641.5 \\
\hline 4 & 12000 & Open 12units on the left, $\# 10 \sim 21$ & 588.0 \\
\hline 5 & 12000 & Open 13 units on the left, \#9 21 & 542.8 \\
\hline 6 & 13000 & Open 10 units on the left, $\# 12 \sim 21$ & 764.4 \\
\hline 7 & 13000 & Open 11 units on the left, $\# 11 \sim 21$ & 694.9 \\
\hline 8 & 13000 & Open 12 units on the left, $\# 10 \sim 21$ & 637.0 \\
\hline 9 & 13000 & Open 13 units on the left, $\# 9 \sim 21$ & 588.0 \\
\hline 10 & 14000 & Open 10 units on the left, \#12 21 & 823.2 \\
\hline 11 & 14000 & Open 11 units on the left, $\# 11 \sim 21$ & 748.4 \\
\hline 12 & 14000 & Open 12 units on the left, $\# 10 \sim 21$ & 686.0 \\
\hline 13 & 14000 & Open 13 units on the left, \#9 21 & 633.2 \\
\hline 14 & 15000 & Open 11 units on the left, $\# 11 \sim 21$ & 801.8 \\
\hline 15 & 15000 & Open 12 units on the left, $\# 10 \sim 21$ & 735.0 \\
\hline 16 & 15000 & Open 13 units on the left, \#9 21 & 678.5 \\
\hline 17 & 16000 & Open 12 units on the left, $\# 10 \sim 21$ & 784.0 \\
\hline 18 & 16000 & Open 13 units on the left, $\# 9 \sim 21$ & 723.7 \\
\hline 19 & 17000 & Open 13 units on the left, $\# 9 \sim 21$ & 768.9 \\
\hline 20 & 17930 & Open 13 units on the left, $\# 9 \sim 21$ & 811.0 \\
\hline
\end{tabular}

Figure 4 shows the proportions of suitable area for different opening modes under high-flow conditions. The calculation results show that when the discharge was $12000 \mathrm{~m}^{3} / \mathrm{s}, 13000 \mathrm{~m}^{3} / \mathrm{s}$, and $14000 \mathrm{~m}^{3} / \mathrm{s}$, the proportion of suitable area showed a parabolic trend with the increase in number of units. When the discharge was $12000 \mathrm{~m}^{3} / \mathrm{s}$, the proportion of suitable area with 11 open units on the left was the largest $(79.4 \%)$, which was $8.7 \%$ larger than the value for all open units and $15 \%$ larger than the value for the lowest number of open units. Opening 12 units on the left yields approximately identical values to opening 11 units with a difference of only $0.1 \%$. When the discharge was $13000 \mathrm{~m}^{3} / \mathrm{s}, 12$ open units on the left had the largest proportion of suitable-flow-velocity area (73.2\%), which was $6.3 \%$ larger than the 
value for all open units and $10 \%$ larger than the value for the lowest number of open units. Opening 11 units on the left was approximately identical to opening 12 units with a difference of only $0.7 \%$. When the discharge was $14000 \mathrm{~m}^{3} / \mathrm{s}$, the proportions of suitable area produced by opening 12 and 13 units on the left were identical (67.3\%), which was $2.1 \%$ larger than the value for all open units and $11.5 \%$ larger than the value for the lowest number of open units. The proportion of suitable area of the lowest number of open units was usually minimal because the discharge of each unit was too high, which resulted in a large area of high velocity that was not suitable for Chinese sturgeon to spawn. For a discharge of $15000 \mathrm{~m}^{3} / \mathrm{s}$, with the increase in number of units, the proportion of suitable area increased, and there was no parabolic trend because the discharge of each unit exceeded $678 \mathrm{~m}^{3} / \mathrm{s}$; thus, on the left side, there was a large area of high velocity, and the effect extended very far, which was not suitable for Chinese sturgeon.

\section{Discussion}

Spawning time and the preferred discharge of Chinese sturgeon. Figure 5 shows the spawning date of Chinese sturgeon downstream of Gezhouba Dam. According to the monitoring data, Chinese sturgeon spawning activity occurs $1 \sim 2$ times every year in October - November. From 1982 to 2002, two spawning events per year were recorded, which occurred in $76.2 \%$ of the years. Since 2003 , most years have featured only one spawning event, with a second spawning event occurring only once on December 2 , 2012. The spawning date was mainly from mid-October to November. The first spawn was concentrated in late October before 2003, mid-November in 2003-2006 and late November since 2007. Therefore, the spawning date has become gradually delayed ${ }^{23}$. The second spawning was concentrated between late October and mid-November, generally occurring $2 \sim 27$ days after the first spawning with an average of 15 days later. To date, the last spawning of Chinese sturgeon occurred on November 24, 2016, and no natural reproduction of Chinese sturgeon was observed downstream of Gezhouba Dam in 2017-2019.

Figure 6 shows daily discharge of the Chinese sturgeon during the spawning day downstream of Gezhouba Dam. The highest discharge of the first spawning was $27290 \mathrm{~m}^{3} / \mathrm{s}$ on October 15,1990 , and the lowest discharge was $5810 \mathrm{~m}^{3} / \mathrm{s}$ on November 23, 2009. The highest discharge of the second spawning was $18170 \mathrm{~m}^{3} / \mathrm{s}$ on November 1,2000 , and the lowest discharge was $5590 \mathrm{~m}^{3} / \mathrm{s}$ on December 2 2 2012. Since the spawning date gradually became delayed, the discharge of the first spawning showed a downward trend overall. The spawning discharge was less than $12000 \mathrm{~m}^{3} / \mathrm{s}$ after 2002. Most spawning dates featured discharges above $12000 \mathrm{~m}^{3} / \mathrm{s}$ before 2002 , which accounted for $75 \%$; discharges above $15000 \mathrm{~m}^{3} / \mathrm{s}$ accounted for $55 \%$, and discharges above the design discharge of $17930 \mathrm{~m}^{3} / \mathrm{s}$ accounted for $25 \%$. The second spawning had a lower discharge than the first spawning; discharges above $12000 \mathrm{~m}^{3} / \mathrm{s}$ accounted for $52.9 \%$, those above $15000 \mathrm{~m}^{3} / \mathrm{s}$ accounted for $17.6 \%$, and a discharge above $179300 \mathrm{~m}^{3} / \mathrm{s}$ occurred only once on November 1, 2000.

Changes in the spawning grounds of Chinese sturgeon. Before the closure of Gezhouba Dam Water Conservancy in 1981, the spawning grounds of the Chinese sturgeon extended from the lower reaches of 
Jinsha River to the upper reaches of Yangtze River, and the main spawning grounds were concentrated from Pingshan to Hejiang ${ }^{24}$.

After the closure of Gezhouba Dam, Chinese sturgeon selected a new spawning ground downstream of Gezhouba Dam. Many scholars studied the distribution of the new spawning ground of Chinese sturgeon using the stomach-content analysis of egg-eating fish, ultrasonic telemetering and tracing, and egg harvesting at the bottom of the river ${ }^{25-27}$. During 1983-1995, the range of spawning ground of the Chinese sturgeon extended approximately $30 \mathrm{~km}$ from Gezhouba Dam to Xiaoting, and spawning mainly concentrated in the approximately $12 \mathrm{~km}$ reach between Gezhouba Dam and Yanzhiba Islet ${ }^{6}$.

During 1996-2007, the spawning ground was the main channel of Yangtze River from Gezhouba Dam to approximately $2 \mathrm{~km}$ upstream of Yanzhiba Islet, and the main spawning site was within the approximately 4-km reach from Gezhouba Dam to Miaozuii 27,28 . The spawning area could be divided into two parts: upstream spawning area and downstream spawning area; the spawning times and scale of the downstream spawning area were obviously larger than those of the upstream spawning area ${ }^{11,28}$. Because the spawning date was mainly concentrated in October, the spawning discharge was high, the suitable area of the upstream spawning area was small, and the upstream spawning area did not feature favourable locations for Chinese sturgeon to perch; thus, the Chinese sturgeon primarily selected to spawn in the downstream spawning area.

All natural reproduction of Chinese sturgeon has occurred in the upstream spawning area since 2008 29,30 , which was also the main research area of this paper. Since 2008, the natural reproduction date of Chinese sturgeon has been postponed to middle and late November, or even early December, when the discharges were less than $10000 \mathrm{~m}^{3} / \mathrm{s}$. The suitable area of the upstream spawning ground was large. Because Chinese sturgeon migrate as far upstream as possibly for reproduction, they selected to reproduce in the upstream spawning area. The change of spawning grounds may be due to changes in discharge.

Factors affecting spawning of Chinese sturgeon. According to current research, the riverbed topography, bottom substrate, velocity, water temperature, water level, discharge, sediment content and other factors are thought to affect the spawning of Chinese sturgeon. Some researchers emphasized the important role of the water level ${ }^{24}$. Other researchers suggested that the changes in riverbed bottom substrate might have caused positional changes in the critical spawning ground of Chinese sturgeon ${ }^{29,31}$. Some researches indicated that the discharge and water temperatures were necessary conditions for Chinese sturgeon spawning and hatching ${ }^{32}$. Some researchers believed that the delay in the decrease in water temperature caused by the Three Gorges Reservoir and low numbers of reproductively mature individuals have contributed to the failure in natural breeding ${ }^{33,34}$.

Although many variables may contribute to the quality and quantity of the spawning habitat, we focused on the velocity as a key metric because of the direct effect of the velocity on the fish spawning habitat. In addition, the flow velocity can be managed through changes in reservoir operation and the opening mode 
of dam units. In contrast, the temperature, turbidity, and substrate are difficult to manipulate through management actions. The multi-variate nature of the habitat implies that the velocity manipulation alone may not be sufficient, so other factors should also be evaluated in the future because they may work together.

Suitable velocity for Chinese sturgeon. Scholars have evaluated several different approaches to determine a suitable flow velocity for the spawning of Chinese sturgeon. One study based on field measurements concluded that Chinese sturgeon chose an area with a flow velocity of $0.62 \sim 1.16 \mathrm{~m} / \mathrm{s}$ when spawning ${ }^{35}$. The hydrological data and measured velocity of the spawning grounds of the Chinese sturgeon downstream of Gezhouba Dam were analysed to calculate the velocity range of $1.0 \sim 2.0 \mathrm{~m} / \mathrm{s}^{10}$. Some scholars measured the spawning days of Chinese sturgeon on site and concluded that the suitable discharge range for Chinese sturgeon was $1.07 \sim 1.65 \mathrm{~m} / \mathrm{s}^{11}$. In another study, researchers measured the velocity in the spawning ground by $A D C P$ and found that the average velocity of the spawning ground was $0.73 \sim 1.75 \mathrm{~m} / \mathrm{s}^{13}$. A numerical modelling study retrieved the flow field during historical detection days and concluded that the suitable velocity range of Chinese sturgeon was $1.1 \sim 1.7 \mathrm{~m} / \mathrm{s}^{12}$. In a hydrodynamic simulation of the spawning ground of Chinese sturgeon, the authors concluded that the most suitable velocity range was $0.97 \sim 1.48 \mathrm{~m} / \mathrm{s}^{36}$. In another numerical modelling study, researchers simulated the water level and velocity by a 2-dimensional hydraulic model and found that a velocity of $1.06-1.56 \mathrm{~m} / \mathrm{s}$ was suitable for the spawning of Chinese sturgeon ${ }^{37}$. These results confirmed the preference of Chinese sturgeon for a range of flow velocity while spawning, but the estimated suitable ranges differ due to differences in research precision and methods.

This study established a three-dimensional numerical model for the bottom velocity of the spawning ground of Chinese sturgeon downstream of the Gezhouba Dam. The opening mode of the dam units was considered in detail, and the model was used to simulate the flow field of the Chinese sturgeon monitored in the field. The results show that most of the sturgeon signals appeared in the velocity range of $0.6 \sim$ $1.5 \mathrm{~m} / \mathrm{s}$. Therefore, this range was treated as the velocity threshold of the Chinese sturgeon, and it was consistent with the ranges proposed by most other researchers.

\section{Conclusions}

Based on the field monitoring results of 2016-2019, the FLOW-3D model was used to simulate the flow field of monitored sturgeon signals, and it was concluded that the preferred velocity range for Chinese sturgeon was $0.6-1.5 \mathrm{~m} / \mathrm{s}$. Under a given discharge, the suitable-velocity area was maximal when all units of the Dajiang Plant of Gezhouba Dam were open, and the conditions were more favourable when the units on the left side were open. When the discharge was less than $12000 \mathrm{~m}^{3} / \mathrm{s}$, the proportion of suitable area slightly fluctuated at approximately $96.2 \%$; when the discharge was $12000 \mathrm{~m}^{3} / \mathrm{s}$, the suitable area rapidly decreased with increasing discharge. Moreover, for different opening modes at high flows, at discharges of $12000 \sim 13000 \mathrm{~m}^{3} / \mathrm{s}$, opening $11 \sim 12$ units on the left side was the best; at a discharge of $14000 \mathrm{~m}^{3} / \mathrm{s}$, opening $12 \sim 13$ units on the left side was the best; when the discharge reached 
$15000 \mathrm{~m}^{3} / \mathrm{s}$, opening 14 units was the best. The optimal scheme for the opening mode of the units at different discharges was analysed, and the results provide new ideas for the protection and ecology conservation of Chinese sturgeon.

\section{Methods}

Study area. Field surveys have shown that the only known spawning ground is located in the section between Gezhouba Dam and Miaozui, which is approximately $4 \mathrm{~km}$ downstream of Gezhouba Dam ${ }^{11}$. Therefore, the area between Gezhouba Dam and Miaozui was selected for investigation in this study, as shown in Fig. 7. Figure 7a shows the location of Yangtze River and Hubei Province in China; Fig. 7b shows the location of Gezhouba Dam in Hubei Province; Fig. 7c shows general condition of spawning ground downstream Gezhouba Dam. The Gezhouba Dam Project have 21 generator units; 14 units with a capacity of 125,000 kilowatts are installed in the Dajiang Plant; 2 units with a capacity of 170,000 kilowatts and 5 units with a capacity of 125,000 kilowatts are installed in the Erjiang Plant ${ }^{22}$. The units are sequentially numbered from the left bank to the right bank (facing downstream). The numbers of Erjiang Plant units are \#1 \#7, and the numbers of Dajiang Plant units are \#8 \#21.

This area was divided into several cross-sections (Fig. 7c), and the velocity of the cross-section was measured with a 300-kHz acoustic Doppler velocity profiler (ADCP). In addition, acoustic imaging sonar monitoring was performed in this area. According to the monitoring results from 2016 to 2019, most of the Chinese sturgeon signals appeared within $700 \mathrm{~m}$ below the Dajiang Plant units of Gezhouba Dam, as shown in the red box in Fig. 1c. Moreover, according to the field investigation, the area of the spawning ground further decreased in recent years because most of the spawning behaviour of Chinese sturgeon has occurred in the red box in Fig. 7c since $2008^{29,30}$. Hence, the range of $700 \mathrm{~m}$ downstream of the Dajiang Plant units was the key area in this study. This area is shown in Fig. 7d, which shows a bathymetric map of this area, and the colour shading and contours represent the water depth when the water level downstream from the dam was $41.2 \mathrm{~m}$. The units on the right side are \#8 \#15, and the corresponding water area under the units was shallow, mostly 7-10 m. There is a deep pit 200 metres from Gezhouba Dam with a water depth of approximately $13 \mathrm{~m}$. Units \#16 \#21 are on the left side, and the corresponding water area is deeper, i.e., $12 \sim 15 \mathrm{~m}$ within $300 \mathrm{~m}$ of the dam; then, the water depth becomes shallower to approximately $10 \mathrm{~m}$.

Numerical model. In this study, we used numerical model FLOW-3D, which is a commercial CFD package based on the finite volume method (FVM) that solves the Reynolds-averaged Navier-Stokes equations ${ }^{38}$. It can effectively estimate the flow structure and velocity distribution in different water layers ${ }^{39}$.

Boundary and initial conditions. The upstream boundary condition used the known discharge based on releases from Gezhouba Dam. The pressure boundary was used for the dowstream boundary and set to the water level. The water surface was a free surface, using a pressure boundary, given standard atmospheric pressure. The wall boundary was used for the solid boundary of the bottom and both sides. The initial condition was the water level, and the initial velocity was 0 . 
Mesh construction. A hexahedral orthogonal grid was used to mesh the model, which can iteratively define a base mesh to fit the surface geometries. The finite volume method was used to discretize the governing equation, and the GMRES algorithm was used to solve the Eq. $4^{0}$. The mesh sizes were selected to respect the requirements of the grid convergence index (GCl) method to test the spatial convergence ${ }^{41}$. The $\mathrm{X}$-axis direction and $\mathrm{Y}$-axis direction mesh sizes were $3-8 \mathrm{~m}$, and the $\mathrm{Z}$-axis direction mesh sizes were 1-2 m.

Model evaluation. The measured velocity data from downstream of Gezhouba Dam were used to evaluate the model. The discharge of Gezhouba Dam was $12000 \mathrm{~m}^{3} / \mathrm{s}$, and the water level downstream from the dam was $41.2 \mathrm{~m}$. The comparisons of the bottom velocity of the measured and model values for cross-Sect. $1 \sim 6$ are presented in Fig. 8. From Fig. 8, the distribution of flow velocity of each crosssection was in good agreement, especially in the Dajiang River area, where the latest spawning ground of the Chinese sturgeon was located. The errors of the model and measured values were generally less than $0.2 \mathrm{~m} / \mathrm{s}$, and the maximum error was $0.43 \mathrm{~m} / \mathrm{s}$, which appeared next to the dividing dike in cross-Sect. 3 . The two-tailed t-test permutation of the model and measured values showed no significant difference: $\mathrm{P}$ $=0.45>0.05$. Therefore, the model simulation was reasonable and acceptably simulated the water flow characteristics of the spawning ground of Chinese sturgeon.

Acoustic monitoring. Acoustic imaging sonar is a fast and effective method to study Chinese sturgeon because it can monitor the number and distribution of fish without approaching and harming the fish ${ }^{42}$. For acoustic monitoring, this paper used a dual-frequency identification (DIDSON) imaging sonar system, which is widely used in fishery management, structural detection, pipeline leakage identification, underwater monitoring, underwater searching, underwater security inspection, etc. ${ }^{43}$.

The main monitoring area was approximately $4 \mathrm{~km}$ long between Gezhouba Dam and Miaozui. During the investigation, the sonar transmitter was fixed to the side of the survey vessel and located $0.3 \mathrm{~m}$ below the water surface. A GPS device produced by the Garmin company was used for navigation and positioning. We continuously performed monitoring every day from October to January of the following year for $3 \sim 4$ hours with a zigzag survey pattern to ensure full coverage of the spawning ground. The monitoring results were saved in the form of video images, and Chinese sturgeon signals were confirmed by measuring the full length, swimming behaviour, body shape, etc. To reduce the error of judgement and obtain high-accuracy Chinese sturgeon signals, each monitoring signal was confirmed by at least two different researchers.

\section{Declarations}

We thank Tao Huang, Yunqin Bai, Bo Li and Nianxiong Yang for their great help for Acoustic monitoring. This work was supported by National Natural Science Foundation of China (51309204).

\section{Authorship contributions}


A. H., Methodology, Investigation, Writing - Original Draft, Data Curation, Formal analysis, Software. J. Y., Conceptualization, Methodology, J. Z., Investigation, Data Curation, Formal analysis. X. G., Investigation, Data Curation. W. J., Conceptualization, Methodology, Supervision, Writing - Review \& Editing, Project administration, Funding acquisition.

\section{Competing Interests:}

The authors declare no competing interests.

\section{Data Availability Statement}

Data are available from the corresponding author upon request.

\section{References}

1. Gao, X. et al. Regime shift in fish assemblage structure in the Yangtze River following construction of the Three Gorges Dam. Sci. Rep.-UK. 9, 4212 (2019).

2. Zhou, X., Chen, L., Yang, J. \& Wu, H. Chinese sturgeon needs urgent rescue. Science. 370, 1175 (2020).

3. Gao, X., Brosse, S., Chen, Y., Lek, S. \& Chang, J. Effects of damming on population sustainability of Chinese sturgeon, Acipenser sinensis: evaluation of optimal conservation measures. Environ. Biol. Fish. 86, 325-336 (2009).

4. Wang, H. Z., Tao, J. P. \& Chang, J. B. Endangered Levels and Conservation Options Evaluations for Chinese Sturgeon, Acipenser sinensis Gary. Resources and Environment in the Yangtze Basin. China. 28, 2100-2108 (2019).

5. Chang, J. B. \& Cao, W. X. History and prospect of conservation on the Chinese Sturgeon in the Yangtze River. Acta Hydrobiologica Sinica. China. 23, 713-720 (1999).

6. Hu, D. G., Ke, F. E., Zhang, G. L., Luo, J. D. \& Gong, M. H. Investigation and Study on Spawning Ground of Chinese Sturgeon under Gezhouba Dam. Freshwater Fisheries. China. 5, 6-10 (1992).

7. Xie, P., Three-Gorges \& Dam Risk to Ancient Fish. Science. 302, 1149-1151 (2003).

8. Ban, X., Gao, X., Diplas, P., Xiao, F. \& Shi, X. T. Suitability analysis of three-dimensional hydraulic factors for spawning habitat of Chinese sturgeon. Advances in Water Science. China. 29, 80-88 (2018).

9. Booker, D. J. Hydraulic modelling of fish habitat in urban rivers during high flows. Hydrol. Process. 17, 577-599 (2003).

10. Ban, X. Applying physical habitat simulation model on the ecological flow decision of Acipenser sinensis natural breeding. Journal of Hydroecology. China. 32, 8-14 (2011).

11. Wei, Q. W. Assessment of reproductive behavior ecology and resources of Chinese sturgeon. Doctor thesis, Chinese Academy of Sciences, Wuhan, 2003. 
12. Yang, D. G. et al. Hydrology status on the spawning ground of Acipenser sinensis below the Gezhouba Dam and its relation to the spawning ground. Acta Ecologica Sinica. China. 27, 862-869 (2007).

13. Zhang, H. et al. Preliminary observation of natural propagation velocity field of Chinese sturgeon under Gezhouba dam. Chinese Fisheries Science. China. 14, 183-191 (2007).

14. Tao, J., Chen, K. Y. \& Wang, D. S. Three-dimensional flow characteristics of spawning ground of Chinese sturgeon. Journal of Hydraulic Engineering. China. 48, 1250-1259 (2017).

15. Wang, Y. K. \& Xia, Z. Q. Three-dimensional Hydraulics Characteristics of Chinese Sturgeon Spawning Site in the Yangtze River. Journal of Sichuan University: Engineering Science Edition. China. 42, 1419 (2010).

16. Wang, Y., Xia, Z. \& Wang, D. Characterization of hydraulic suitability of Chinese sturgeon (Acipenser sinensis) spawning habitat in the Yangtze River: Hydraulic Suitability Of Chinese Sturgeon. Hydrol. Process. 26, 3489-3498 (2012).

17. Wu, F. Y. \& Fu, X. L. The 3-D flow field numerical simulation of Acipenser Sinensis' spawning sites in Gezhouba downstream. Journal of Hydroelectric engineering. China,114-118(2007).

18. Bi, X., Tian, Z. F. \& Yang, M. F. Influence of different operation modes of Gezhouba Hydropower Station on flow conditions of Chinese sturgeon's spawning ground. Yangtze River. China. 47, 25-29 (2016).

19. Huang, M. H., Guo, H., Xing, L. H., Jiang, W. \& Yang, W. Influence of Gezhouba Project Dispatching on the Flow Condition of Chinese Sturgeon's Spawning Ground. Journal of Yangtze River Scientific Research Institute. China. 30, 102-107 (2013).

20. Mao, J. Q., Li, Z., Dai, H. C. \& Ke, Y. Short-term Hydrodynamic feature of Chinese sturgeon spawning ground under reservoir regulation conditions. Journal of Drainage and Irrigation Machinery Engineering. China. 32, 399-403 (2014).

21. Xie, H. B. \& Xu, H. Q. Operation Stability of Gezhouba Hydropower Station after its Capacity Increasing. Large Electric Machine and Hydraulic Turbine. China. 6, 39-43 (2009).

22. Zhao, R. H. Reservoir Regulation of Gezhouba Water Control Project. Central China Electric Power. China. 2, 24-29 (1991).

23. Shen, Y. X. et al. An improved habitat model to evaluate the impact of water conservancy projects on Chinese sturgeon (Acipenser sinensis) spawning sites in the Yangtze River, China. Ecol. Eng. 104, 165-176 (2017).

24. YARSG, Y. A. R. S. et al. (eds) The biology of the sturgeons and paddlefish in the Yangtze River and their artificial propagation. (Sichuan Scientific and Technical Publishing House: Chengdu, 1988).

25. Wei, Q. W. et al. Biology, fisheries, and conservation of sturgeons and paddlefish in China. Environment Biology Fish. 48, 241-255 (1997).

26. Wei, Q. W. et al. Using drift nets to capture early life stages andmonitor spawning of the Yangtze River Chinese sturgeon(Acipenser sinensis). J. Appl. Ichthyol. 25, 100-106 (2009). 
27. Yang, D. G. et al. Distribution and movement of Chinese sturgeon, Acipenser sinensis, in spawning ground located below the Gezhouba Dam during spawning seasons. J. Appl. Ichthyol. 22, 145-151 (2006).

28. Zhang, H. et al. Spatial structure and bottom characteristics of theonly remaining spawning area of Chinese sturgeon in the Yangtze River. J. Appl. Ichthyol. 27, 251-256 (2011).

29. Du, H. et al. Changes of bottom substrate characteristics in spawning ground of Chinese sturgeon downstream the Gezhouba Dam from impounding of three gorge reservoir. Acta Ecologica Sinica. China. 35, 3124-3131 (2015).

30. Wu, J. M. et al. From continuous to occasional: Small-scale natural reproduction of Chinese sturgeon occured in the Gezhouba spawning ground. Journal of Fishery Sciences of China. China. 24, 425431 (2017).

31. Du, H. et al. Bottom substrate attributes relative to bedform morphology of spawning site of Chinese sturgeon Acipenser sinensis below the Gezhouba dam: Bottom substrate attributes relative to bedform morphology. J. Appl. Ichthyol. 27, 257-262 (2011).

32. Wang, P. F. et al. An improved habitat model to evaluate the impact of water conservancy projects on Chinese sturgeon (Acipenser sinensis) spawning sites in the Yangtze River, China.Ecol. Eng.,165176(2017).

33. Chang, T. et al. Using adaptive resolution imaging sonar to investigate Chinese sturgeon (Acipenser sinensis Gray, 1835) behavior on its only spawning ground in the Yangtze River. J. Appl. Ichthyol. 33, 681-688 (2017).

34. Tao, Y. W., Wang, Y. K., Wang, D., Wu, J. C. \& Ni, L. L. Changes of water temperature under dam of Three Gorges Reservoir and its effect on fish spawning. Journal of Hydroelectric Power. 37, 48-55 (2018).

35. Chen, Y. B. Study on Ecological Hydrological Mechanism and Protection Countermeasures of Three Gorges Reservoir Affecting the Breeding of Chinese Sturgeon. Doctor thesis, Chinese Academy of Sciences, Wuhan 2007.

36. Wang, Y., Dai, H. C. \& Dai, L. Q. Hydrodynamic characteristics of spawning ground of Chinese sturgeon after impoundment operation of the Three Gorges Reservoir. Journal of Hydroelectric Engineering. China. 32, 122-126 (2013).

37. Yi, Y. J., Sun, J. \& Zhang, S. H. A habitat suitability model for Chinese sturgeon determined using the generalized additive method. J. Hydrol. 534, 11-18 (2016).

38. Flow Science, I. Flow-3D User Manual: v11.1. Vol. 47 Santa Fe, New Mexico, USA 2012).

39. Chen, S. C. \& Tfwala, S. S. Performance Assessment of FLOW-3D and XFlow in the Numerical Modelling of Fish-bone Type Fishway Hydraulics. in 7th IAHR International Symposium on Hydraulic Structures Aachen, Germany 2018).

40. Moukalled, F., Mangani, L. \& Darwish, M. The Finite Volume Method in Computational Fluid Dynamics: An Advanced Introduction with OpenFOAM ${ }^{\circledR}$ and Matlab(Springer International Publishing, 2015). 
41. Celik, I. B. et al. Procedurefor estimation and reporting of uncertainty due to discretization in CFD applications. J. Fluids Eng. Trans. 130, 780011-780014 (2008).

42. Tao, J. P., Qiao, Y., Tan, X. C. \& Chang, J. B. Species identification of Chinese sturgeon using acoustic descriptors and ascertaining their spatial distribution in the spawning ground of Gezhouba Dam. Chinese Sci Bull. 54, 2975-2982 (2009).

43. Belcher, E., Hanot, W. \& Burch, J. Dual-Frequency Identification Sonar (DIDSON). Proceedings of the 2002 International Symposium on Underwater Technology. 2002 2002-01-01; 2002. p. 187-192.

\section{Figures}

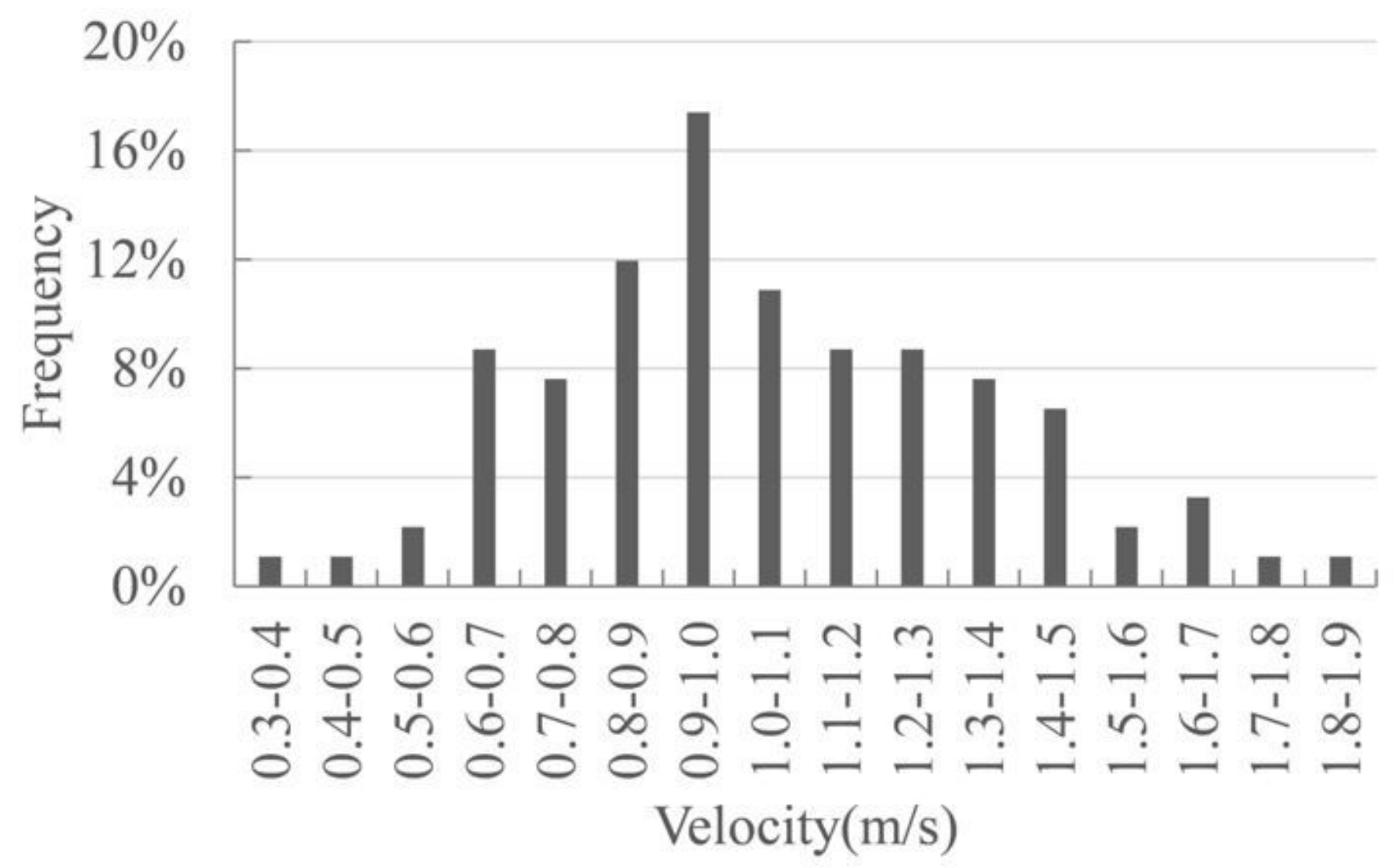

Figure 1

Plots of the frequency for the different flow velocity ranges of Chinese sturgeon signals. 


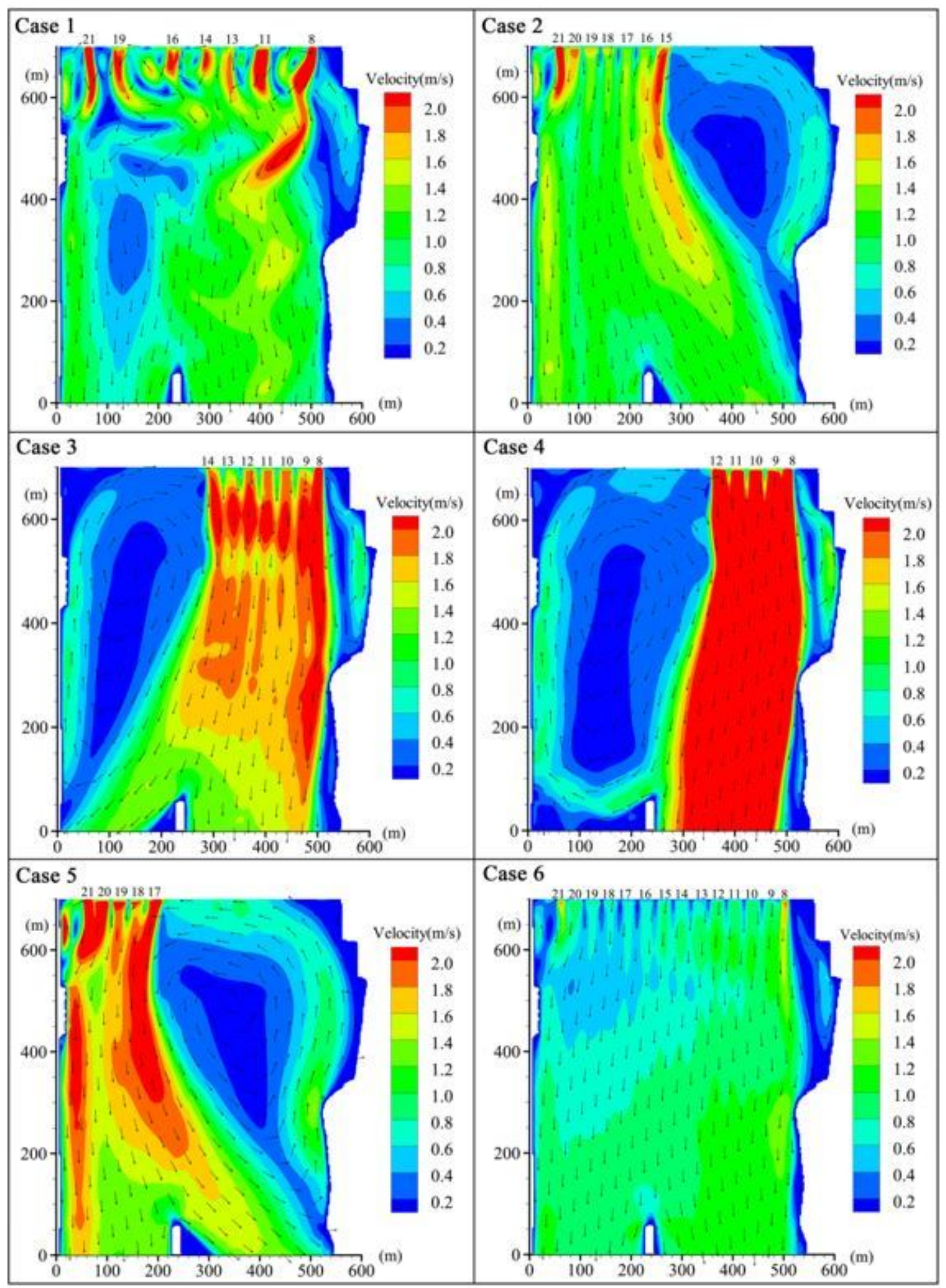

\section{Figure 2}

Flow field of the spawning ground in different opening modes with identical discharge, where the numbers at the top of each picture are the number of the unit to open, and the arrows indicate the direction of the water flow. Note: The designations employed and the presentation of the material on this map do not imply the expression of any opinion whatsoever on the part of Research Square concerning 
the legal status of any country, territory, city or area or of its authorities, or concerning the delimitation of its frontiers or boundaries. This map has been provided by the authors.

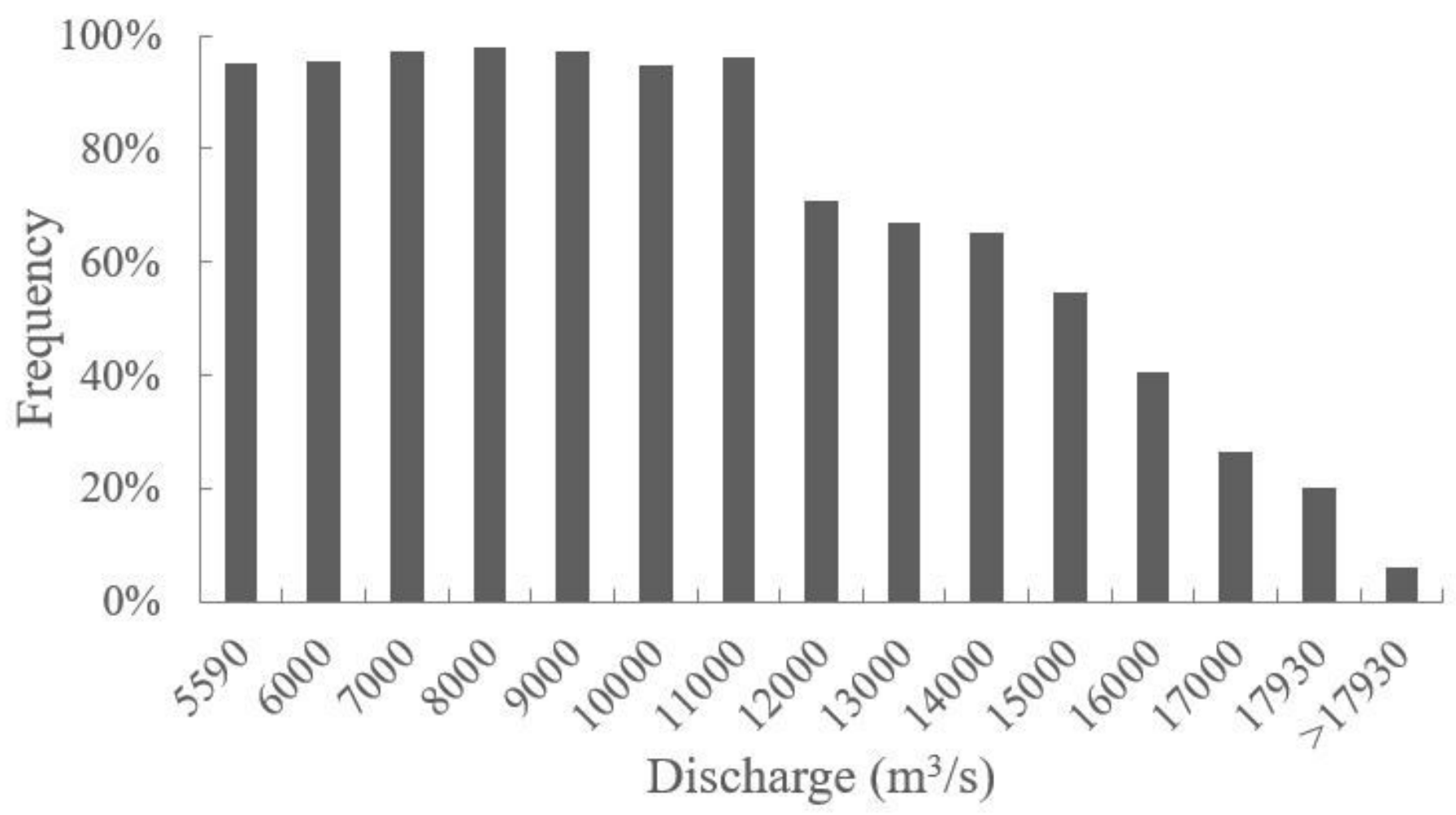

Figure 3

Proportions of the suitable-velocity area with all units opened under different discharges. 


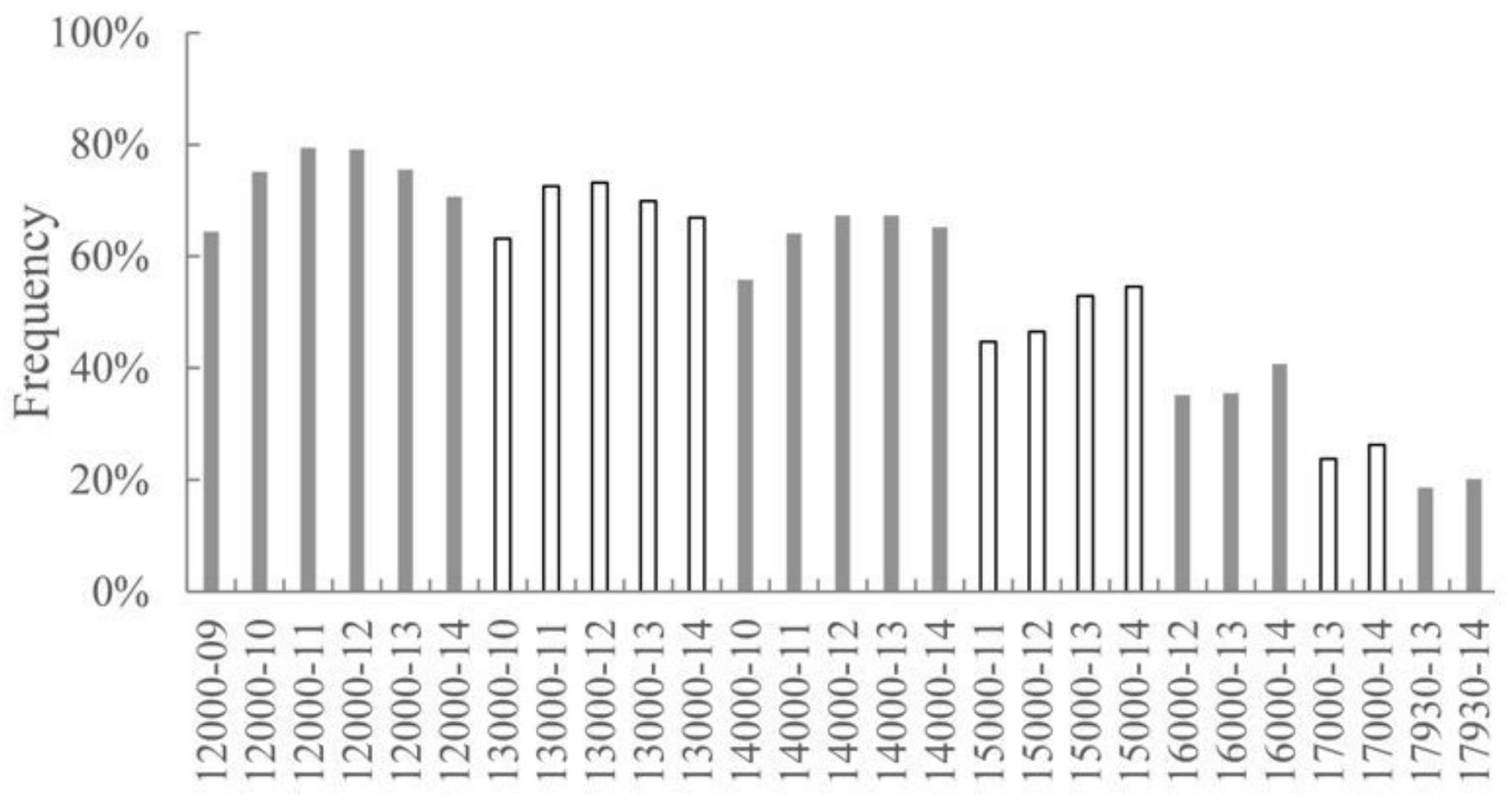

Different model at high flow

Figure 4

Proportions of the suitable area for different opening modes under high-flow conditions, where 12000-09 on the $x$-axis indicates that the discharge is $12000 \mathrm{~m} 3 / \mathrm{s}$, and 9 units are open on the left.

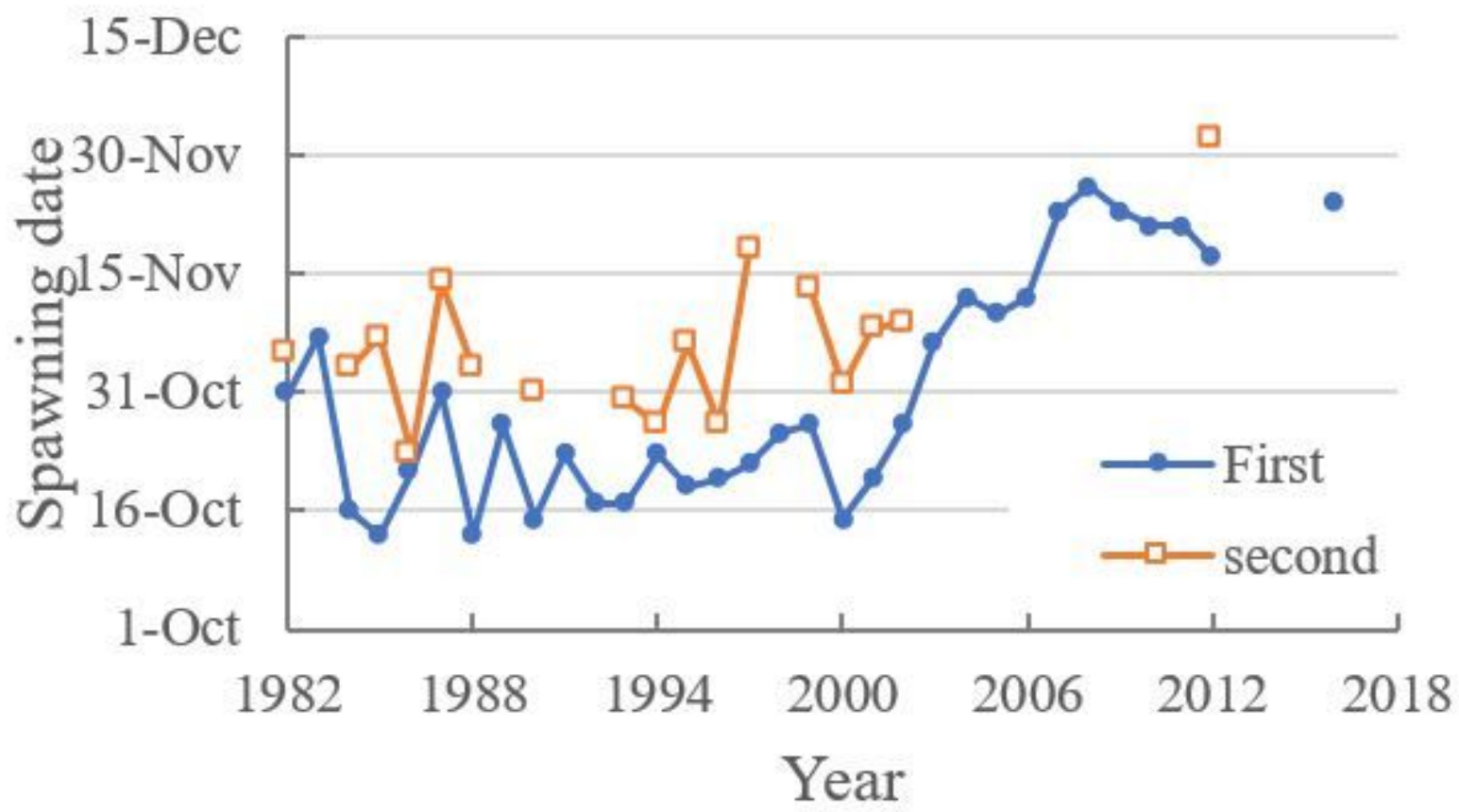

Figure 5 
Spawning date of the Chinese Sturgeon downstream of Gezhouba Dam

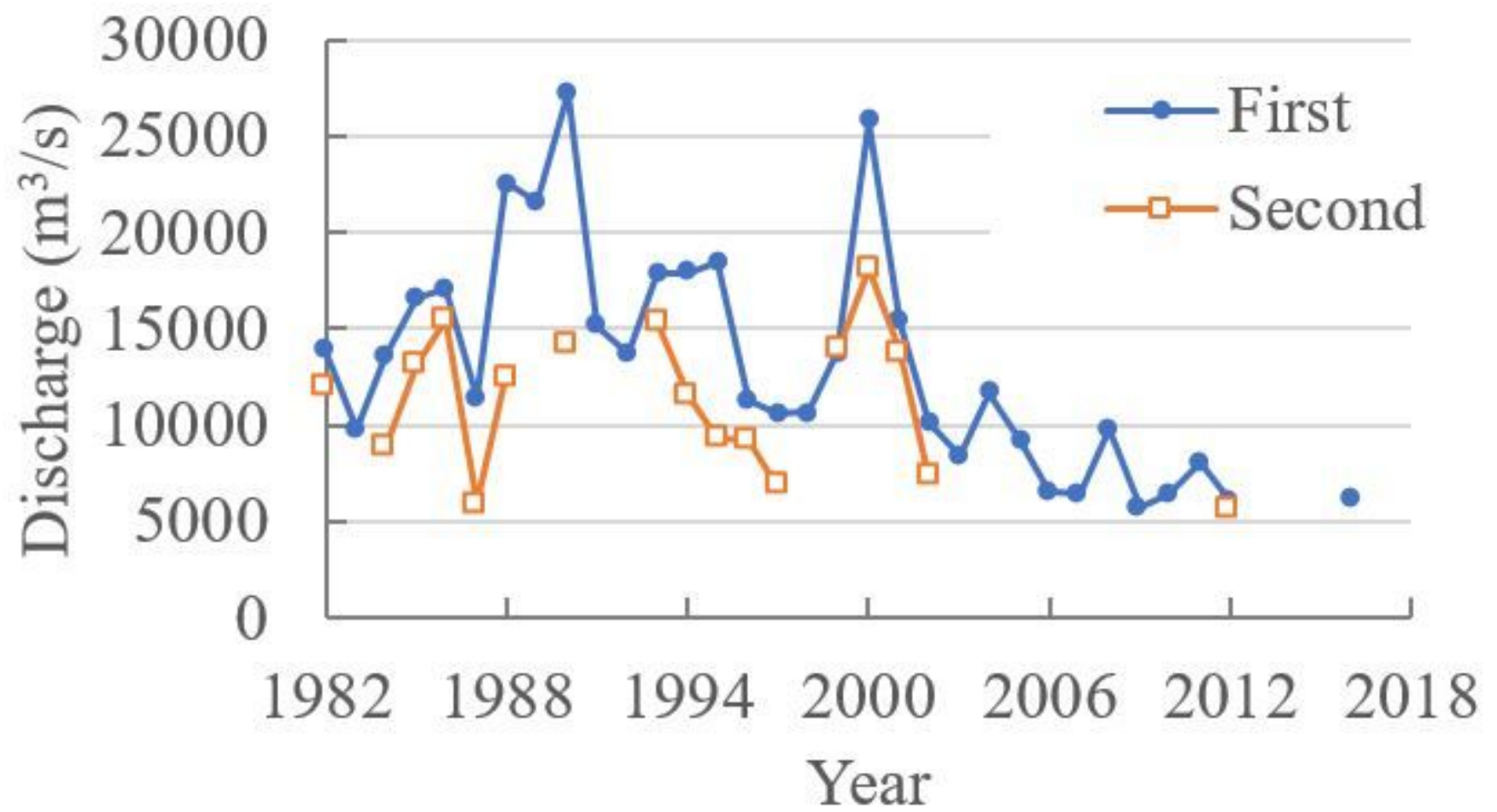

Figure 6

Daily discharge of the Chinese sturgeon during the spawning day downstream of Gezhouba Dam. 

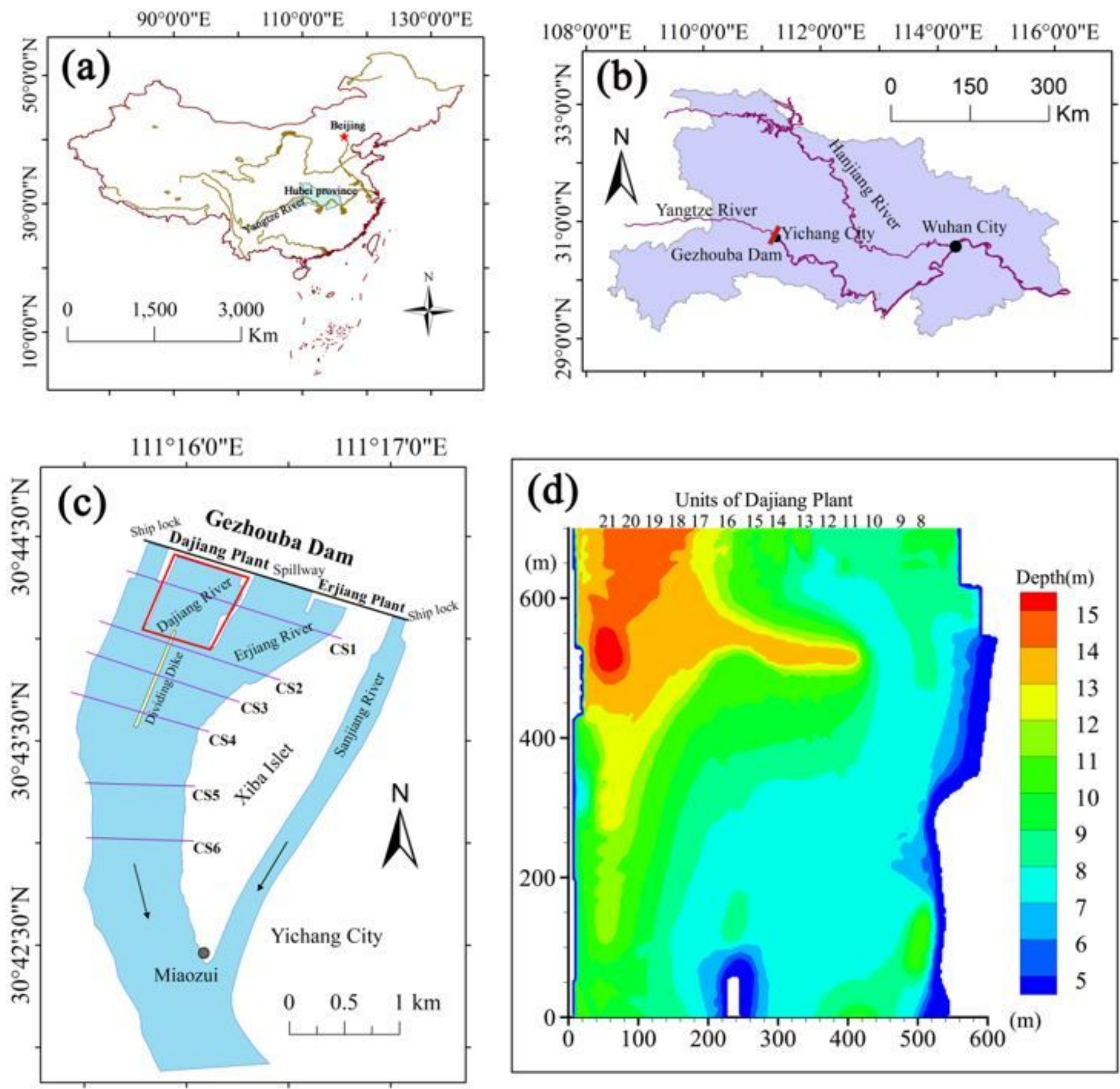

\section{Figure 7}

Location of the study area. (a) Location of Yangtze River and Hubei Province Note: The designations employed and the presentation of the material on this map do not imply the expression of any opinion whatsoever on the part of Research Square concerning the legal status of any country, territory, city or area or of its authorities, or concerning the delimitation of its frontiers or boundaries. This map has been provided by the authors. 

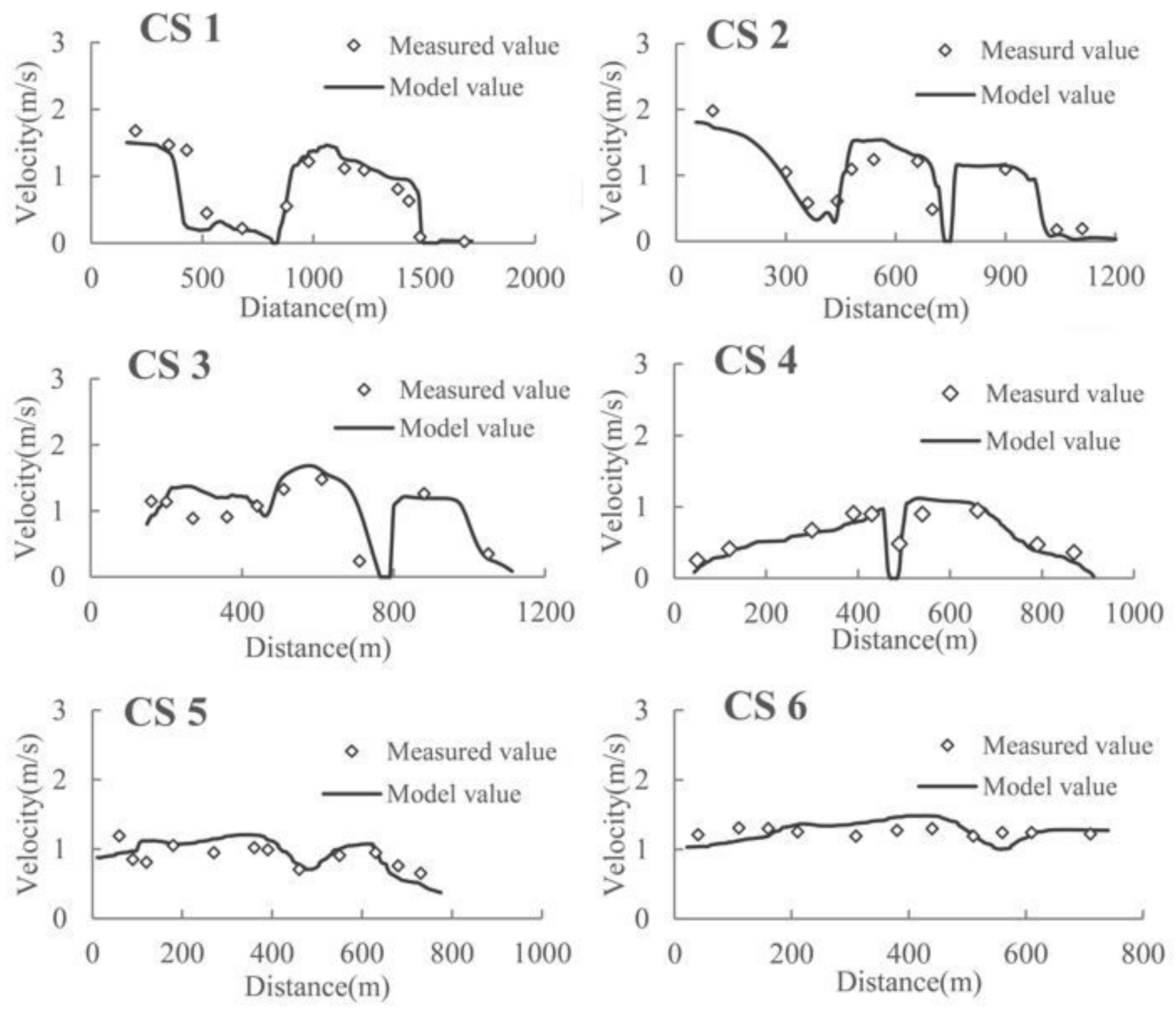

Figure 8

Plots of the measured and model values for cross-sections 1 6 (Figure 7c) 